\title{
BACTERIAL ISOLATES AND ANTIBIOTIC SENSITIVITY PATTERNS IN CHOLEDOCHAL BILE COLLECTED DURING ERCP: A REPORT FROIM CENTRAL INDIA.
}

KEY WORDS: extra hepatic cholestasis, endoscopic retrograde cholangiography, cholangitis, infections
Mohd Talha Noor*

Vishal Goyal

Praveen

Vasepalli

Mayank Jain

Bhagwan Singh

Thakur

\section{Nishat Gorie}

MD, DM, Department of Gastroenterology, Sri Aurobindo Institute of Medical Sciences, Indore (M.P.), India. 453555. *Corresponding Author

Department of Gastroenterology, Sri Aurobindo Institute of Medical Sciences, Indore (M.P.), India. 453555

Department of Gastroenterology, Sri Aurobindo Institute of Medical Sciences, Indore (M.P.), India. 453555

Department of gastroenterology, Arihant hospital and research centre, Indore, India. 452009

Department of Gastroenterology, Sri Aurobindo Institute of Medical Sciences, Indore (M.P.), India. 453555

Department of Microbiology, Sri Aurobindo Institute of Medical Sciences, Indore (M.P.), India. 453555

Temporal shifts have been known to occur in antibiotic sensitivity patterns of organisms causing cholangitis. The aim of this prospective study conducted on 100 patients of extra hepatic biliary obstruction (EHBO) was to identify the common microorganisms cultured from bile obtained during Endoscopic retrograde cholangiography and to study their local sensitivity pattern. Sixty six patients had growth in bile culture, the maximum growths amongst all micro-organisms were of Escherichia coli (40.9\%) and Pseudomonas aeruginosa (40.9\%). Growth rates were significantly higher in patients with non- malignant causes of biliary obstruction than those with malignant causes. Polymixins had the highest sensitivity to cultured bacteria followed by aminoglycosides and Imipenem. Study of culture \& sensitivity pattern helps in deciding empirical antibiotic therapy in patients with cholangitis and it should be based on local sensitivity patterns

\section{INTRODUCTION}

The continuous flushing action of bile and the bacteriostatic effects of bile salts help to keep the bile duct sterile ${ }^{1}$.However, in case of biliary obstruction, there is increase in pressure in bile duct due to bile stasis. This milieu is suitable for colonization and replication of bacteria. Eventually these bacteria spread hematogenously cause systemic infections ${ }^{2}$. In advanced biliary obstruction with sepsis and multi organ dysfunction, mortality can be as high as $10 \%^{3,4}$.

Studies have highlighted that blood cultures can be negative in more than half of the patients with acute cholangitis'. In suspected cholangitis, it is advisable to start empirical antibiotics before contemplating biliary drainage using endoscopic retrograde cholangiopancreatography (ERCP). Selection of antibiotic is based on numerous factors like the severity of the cholangitis, the presence of renal and hepatic dysfunction, a recent history of antimicrobial therapy, local susceptibility pattern and the biliary penetration of the antimicrobial agent ${ }^{2,5}$. Gram-negative bacilli like Escherichia coli are the most common bacterial isolates from infected bile ${ }^{6,7}$. Since Gram negative organisms are rapidly developing multi-drug resistance, the choice of appropriate empirical antimicrobial therapy has become more complicated.

The present study was conducted to study the bacterial isolates cultured from bile during ERCP and their local sensitivity pattern.

\section{MATERIALS AND METHODS}

This is a prospective observational study, performed at the Department of Gastroenterology of Sri Aurobindo Medical College and Postgraduate Institute, Indore, India from January 2016 to November 2017. The protocol was approved by the Institutional Ethics Committee prior to initiation of the study.

We recruited all patients of extra-hepatic biliary obstruction undergoing ERCP at our center. Informed written consent was taken from all the patients. Patients less than 18 years of age or those not consenting for participation in the study were excluded. As per our department policy, all patients with biliary obstruction +/- suspected cholangitis are started on empirical antibiotics namely ceftriaxone in a dose of 1 gram 12 hourly. Antibiotics are escalated based on culture reports and clinical improvement.

The diagnosis of acute cholangitis was made according to Tokyo guidelines 2013 (TG13) ${ }^{8}$. Biliary obstruction was detected by dilated intra/extra-hepatic biliary system on imaging (abdominal ultrasound +/- computed tomography of the abdomen). The diagnosis of malignant biliary obstruction was based on biliary cytology, ampullary biopsy or Ultra sound guided/ Endoscopic ultrasound guided fine needle aspiration cytology.

ERCP was performed using a side viewing endoscope (TJF$150^{\mathrm{TM}}$, Olympus, Tokyo, Japan). As per our institutional policy, the scope is routinely disinfected according to the guidelines and sterilization is checked using regular smear tests and cultures every 3 months. All accessories used for ERCP were regularly sterilized using appropriate sterilizing methods. Once guide-wire cannulation is established, bile is aspirated by placing a single-use, $5.5 \mathrm{~F}$ standard sphincterotome catheter (Ultratome ${ }^{\mathrm{TM}} \mathrm{XL}$, Boston scientific, Alajuela, Costa Rica) into the bile duct before the injection of contrast agent. After discarding first $2 \mathrm{ml}$ of bile, approximately 2 to $6 \mathrm{ml}$ of bile is collected and transferred in a sterile tube. Collected bile is transported to the microbiology laboratory under all aseptic precautions. Within 10 minutes of collection the bile sample is inoculated on blood agar and Mac conkey agar. The culture is reported at 24 and 72 hours after inoculation. In case any bacteria is isolated, antibiotic sensitivity testing is done using broth micro-dilution method.

The data recorded included age, sex, clinical symptoms, blood investigations including liver and renal biochemistry, radiological tests and history of prior antibiotic usage or attempted biliary drainage in the preceding 7 days.

Statistical analysis was done using SPSS (Statistical Package 
for Social Sciences, release 20.0, standard version; SPSS Inc.) software computer package. Categorical data were presented as proportions. For qualitative data, frequency and percent distribution were calculated and for comparison between groups chi-square test was used. All $p$ values were based on two-tailed tests. A $p$ value $<0.05$ was considered significant. One way ANOVA test was used to correlate diagnosis and growth rate.

\section{RESULTS}

A total of 100 patients (48\% males, mean age $53.53 \pm 14.65$ years, range- 18 to 80 years) were included in the study. Jaundice was seen in $77(77 \%)$ patients, abdominal pain in 72 $(72 \%)$ patients, fever in $44(44 \%)$ patients, weight loss in 27 $(27 \%)$ patients and altered sensorium in $3(3 \%)$ patients.

Out of the 100 patients included in our study, 44\% had cholangitis. Fifty six percent had non-malignant causes of biliary obstruction [table 1]. Fifteen (15\%) of the patients had undergone previous ERCP with stenting at the time of presentation. Forty four percent of patients received empirical antibiotics prior to undergoing ERCP. There was a mortality of $5 \%$ in our study.

Out of the 100patients, 66 patients had growth in bile culture, out of which 9 patients had growth of two microorganisms. Thus a total of 75 microbial growths were obtained. The maximum growths amongst all micro-organisms were of Escherichia coli $(40.9 \%)$ and Pseudomonas aeruginosa $(40.9 \%)$ as shown in table 2 .

The difference in growth rates in patients having cholangitis and those not having any cholangitis (61.36\% vs $69.64 \%$ ) was not statistically significant $(p=0.288)$. Similarly, there was no statistical difference in bacterobilia in patients who had undergone previous ERCP with stenting to those who had not undergone the same previously ( $60 \%$ vs. $67 \%, \mathrm{P}=0.301)$. However, growth rate in patients with non-malignant causes of biliary obstruction were $70.76 \%$ as compared to $57.14 \%$ in those with malignant causes of biliary obstruction, the difference being statistically significant $(p=0.03)$. We found no significant difference in growth rates in bile culture, between patients who had received antibiotics prior to ERCP and those who did not $(67.92 \%$ vs. $63.83 \%, \mathrm{P}=0.599)$. Patients having bacterobilia had a mortality of $6 \%(4 / 66)$ during the hospital stay, as compared to only $3 \%(1 / 34)$ to those who did not have bacterobilia. The difference between two groups was statistically not significant. $(\mathrm{P}=0.173)$.

\section{Antibiotic Sensitivity}

Out of 75 microbial growths obtained from 66 positive bile cultures in our study, 70 were gram negative bacterial growths, 4 were gram positive bacterial growths and 1 patient had a fungal growth.

In our study, polymyxins (Colistin - $96.97 \%$ and Polymyxin B$85.71 \%$ ) had the highest sensitivity to gram negative bacteria, followed by aminoglycosides (Amikacin- $82.09 \%$, Gentamicin- $80.95 \%$, and Tobramycin- $77.42 \%$ ) and Imipenem (71.64\%).Details have been shown in table 3 .

\section{DISCUSSION}

Acute cholangitis can be life threatening and requires urgent biliary drainage and empirical antibiotics. A recent large scale study indicated the mortality rate (30-day all-cause mortality rate) of $2.4 \%, 4.7 \%, 8.4 \%$ by TG 13 severity grade 1 , 2 \& 3 respectively ${ }^{9}$. In patients with septic shock appropriate antimicrobial therapy should be administered within an hour ${ }^{10}$. A review of previous studies of patients undergoing biliary intervention has shown bacterobilia rates between $35-$ $80 \%$. Growth rates in cholangitis patients have been found to be more variable, in the range of $28-93 \%{ }^{5,6,11-18}$. In our study, we found bacterobilia in $66 \%$ of patients and in patients having cholangitis it was found to be $61.36 \%$. This high variability could be due to difference in study designs. For example, in a study by Sahu MK et $\mathrm{al}^{12}$ none of the patients were given antibiotics prior to intervention, while in our study and that of Kaya MK et $\mathrm{al}^{5}$ antibiotics were given empirically to patients with cholangitis. . The difference in growth rates in patients having cholangitis and those not having any cholangitis (61.36\% vs $69.64 \%$ ) was not statistically significant ( $p=0.288)$. Similar findings have been seen in the study by Kaya $\mathrm{M}_{\text {et }} \mathrm{al}^{5}$. However, in several other previous studies ${ }^{6,15,17}$ growth rates were significantly higher in cholangitis group. The likely explanation for this finding is that antibiotics given prior to ERCP seem to reduce the probability of culturing the microorganisms causing cholangitis.

The growth rate in patients with non-malignant causes of biliary obstruction were $70.76 \%$ as compared to $57.14 \%$ in those malignant causes of biliary obstruction, the difference being statistically significant $(p=0.03)$. . In the study by Kaya $\mathrm{M}$, et $\mathrm{al}^{5}$, there was no significant difference between the two groups in rates of bacterobilia ( $49 \%$ vs. $58 \%$ ). In a study by Negm AA et $\mathrm{al}^{19}$ also, there was no significant difference between these two groups, however it did show higher growth rates in benign strictures (84\%) as compared to those with malignant strictures (76\%). Cholangitis more likely to result when a bile duct that already contains bacteria become obstructed, as in most cases with choledocholithiasis. Malignant obstruction is more often complete than obstruction by a benign stricture or bile duct stone and less commonly permits reflux of bacteria from duodenal contents into the bile ducts this could be the reason of higher growth rates seen in patients with benign $\mathrm{EHBO}^{20}$.

The most common organisms cultured from bile have been Escherichia Coli, Pseudomonas aeruginosa and Enterococci in different studies. ${ }^{5,11-14,16,18,19,21}$ In our study Escherichia coli and Pseudomonas aeruginosa were both equally common, followed by Klebsiella pneumonia

Choice of antimicrobials is crucial in management of cholangitis. In the previous studies carbapenems and aminoglycosides have been found to have highest sensitivity to gram negative bacteria cultured from bile..$^{5,11,16,22 .}$ In our study, polymyxins (Colistin - $96.97 \%$ and Polymyxin B$85.71 \%$ ) had highest sensitivity to gram negative bacteria, followed by aminoglycosides (Amikacin- $82.09 \%$, Gentamicin- $80.95 \%$, and Tobramycin- $77.42 \%$ ) and Imipenem (71.64\%). This difference from other studies has been mainly due to the fact that none of these previous quoted studies had checked for in vitro sensitivity to the Polymyxin group of antibiotics.

Interesting findings regarding carbapenem sensitivity were noted in our study. Firstly, carbepenems had a much lower sensitivity rate (Imipenem $-71.64 \%$, Meropenem-47.69\%) than what was seen in previous studies ${ }^{5,11,12}$. Secondly, in our study Imipenem had a much higher sensitivity rate $(71.64 \%)$ as compared to Meropenem (47.69\%), which was not the case in any of the previous studies ${ }^{5,6,14}$. Although it is difficult to point out the exact reason for these findings, but one of the major contributors could be irrational and injudicious use of carbapenem antibiotics in general. These findings can also help us in the choice of empirical antibiotic therapy in future.

The limitations of our study were that anaerobic organisms were not studied in bile samples. Secondly, a larger sample size would be better suited to guide empirical therapy for cholangitis patients.

Acknowledgements: We thank our patients for their support.

The Authors declares that there is no conflict of interest

Grants/other financial support:None. 
PARIPEX - INDIAN JOURNAL OF RESEARCH | Volume - $10 \mid$ Issue - 05 |May - $2021 \mid$ PRINT ISSN No. 2250 - 1991 | DOI : $10.36106 /$ paripex

Table 1: Association Of Etiology Of Biliary Obstruction With Bacterial Growth

\begin{tabular}{|c|c|c|c|}
\hline Diagnosis.5 & Growth & \begin{tabular}{|l|} 
No- \\
Growth
\end{tabular} & $\begin{array}{l}\text { Total } N==100 \\
(\%)\end{array}$ \\
\hline $\begin{array}{l}\text { CHOLEDOCHOLITHIA } \\
\text { SIS } \\
\end{array}$ & 40 & 16 & $56(56 \%)$ \\
\hline $\begin{array}{l}\text { CARCINOMA GALL } \\
\text { BLADDER } \\
\end{array}$ & 10 & 6 & $16(16 \%)$ \\
\hline $\begin{array}{l}\text { PANCREATIC HEAD } \\
\text { CARCINOMA }\end{array}$ & 2 & 1 & $3(3 \%)$ \\
\hline $\begin{array}{l}\text { PERIAMPULLARY } \\
\text { CARCINOMA }\end{array}$ & 5 & 4 & $9(9 \%)$ \\
\hline $\begin{array}{l}\text { CHOLANGIOCARCIN } \\
\text { OMA }\end{array}$ & 1 & 2 & $3(3 \%)$ \\
\hline $\begin{array}{l}\text { HEPATOCELLULAR } \\
\text { CARCINOMA } \\
\end{array}$ & 2 & 1 & $3(3 \%)$ \\
\hline BILE LEAK & 2 & 0 & $2(2 \%)$ \\
\hline \begin{tabular}{|l|} 
CHRONIC CALCIFIC \\
PANCREATITIS \\
\end{tabular} & 1 & 1 & $2(2 \%)$ \\
\hline \begin{tabular}{|l|} 
PANCREATIC \\
PSEUDOCYST \\
\end{tabular} & 1 & 0 & $1(1 \%)$ \\
\hline PORTAL BILIOPATHY & 2 & 1 & $3(3 \%)$ \\
\hline \begin{tabular}{|l|} 
EXTRINSIC \\
MALIGNANT \\
COMPRESSION \\
\end{tabular} & 0 & 1 & $1(1 \%)$ \\
\hline CBD STRICTURE & 0 & 1 & $1(1 \%)$ \\
\hline \multicolumn{4}{|l|}{ (CBD= common bile duct $)$} \\
\hline \multicolumn{4}{|c|}{ Table 2: Micro Organisms grown } \\
\hline \multicolumn{3}{|l|}{ MICRO ORGANISIMS } & $\mathrm{N}(\%)$ \\
\hline \multicolumn{3}{|l|}{ Escherichia coli } & $27(40.9 \%)$ \\
\hline \multicolumn{3}{|c|}{ Pseudomonas aeruginosa } & $27(40.9 \%)$ \\
\hline \multicolumn{3}{|l|}{ Klebsiella pneumonia } & $13(19.7 \%)$ \\
\hline \multicolumn{3}{|l|}{ Citrobacterfreundii } & $2(3.0 \%)$ \\
\hline \multicolumn{3}{|l|}{ Staphylococcus aureus } & $2(3.0 \%)$ \\
\hline \multicolumn{3}{|l|}{ Proteus mirabilis } & $1(1.5 \%)$ \\
\hline \multicolumn{3}{|l|}{\begin{tabular}{|l|} 
Enterococcus \\
\end{tabular}} & $1(1.5 \%)$ \\
\hline \multicolumn{3}{|l|}{ Diptheroids } & $1(1.5 \%)$ \\
\hline \multicolumn{3}{|l|}{ Candida } & $1(1.5 \%)$ \\
\hline
\end{tabular}

Table 3: Antibiotic Sensitivity pattern to Gram Negative Organisms

\begin{tabular}{|l|l|}
\hline Antibiotic Sensitivity & Percentage (\%) \\
\hline Colistin & 96.97 \\
\hline Polymyxin B & 85.71 \\
\hline Amikacin & 82.09 \\
\hline Gentamicin & 80.95 \\
\hline Tobramycin & 77.42 \\
\hline Imipenem & 71.64 \\
\hline Chloramphenicol & 67.65 \\
\hline Meropenem & 47.69 \\
\hline Doripenem & 41.79 \\
\hline Levofloxacin & 37.10 \\
\hline Piperacillin + Tazobactam & 36.76 \\
\hline Ciprofloxacin & 36.36 \\
\hline Cotrimoxazole & 30.30 \\
\hline Ceftazidime + Clavulanic Acid & 27.78 \\
\hline Cefepime & 22.64 \\
\hline Cefotetan & 21.05 \\
\hline Ticarcillin & 18.75 \\
\hline Ticarcillin + Clavulanic Acid & 15.56 \\
\hline Aztreonam & 15.15 \\
\hline Cefoxitin & 14.29 \\
\hline Cefotaxime & 12.82 \\
\hline Ceftazidime & 11.90 \\
\hline Ampicillin Salbactam & 9.09 \\
\hline Cefazolin & 9.09 \\
\hline Amoxyclav & 8.11 \\
\hline & \\
\hline
\end{tabular}

www.worldwidejournals.com|

\begin{tabular}{|l|l|}
\hline Ampicillin & 6.67 \\
\hline Cefuroxime & 6.67 \\
\hline
\end{tabular}

\section{REFERENCES}

1. J.Y.Sung, J.W. Costerton, and E. A. Shaffer, "Defense system in the biliary tract against bacteri

2. Tanaka A, Takada T, Kawarada Y, Nimura Y, Masahiro Y, Miura F, et al. Antimicrobial therapy for acute cholangitis: Tokyo Guidelines. J HepatobiliaryPancreatSurg 2007;14:59-67.PMID: 17252298

3. Lai EC, Mok FP, Tan ES, Lo CM, Fan ST, You KT, et al. Endoscopic biliary drainage for severe acute cholangitis. N Engl J Med 1992;326:1582-6. PMID: 1584258

4. Leung JW, Chung SC, Sung JJ, BanezVP, Li AK. Urgent endoscopic drainage for acute suppurative cholangitis. Lancet 1989;1:1307-9.PMID:2566834

5. Kaya M, Be ta R, Bacalan F, Bacaksiz F, Arslan EG, Kaplan MA. Microbial profile and antibiotic sensitivity pattern in bile cultures from endoscopic retrograde cholangiography patients. World J Gastroenterol 2012;18:35853589.PMID: 22826624

6. Salvador VB, Lozada MC, Consunji RJ. Microbiology and antibiotic susceptibility of organisms in bile cultures from patients with and without cholangitis at an Asian academic medical center.Surg Infect (Larchmt) 2011;12:105-111.PMID:21348769

7. Melzer M, Toner R, Lacey S, Bettany E, Rait G. Biliary tract infection and bacteraemia: presentation, structural abnormalities, causative organisms and clinical outcomes. Postgrad Med J 2007;83:773-776.PMID: 18057178

8. Kiriyama S, Takada T, Strasberg SM, Solomkin JS, Mayumi T, Pitt HA, et al.TG13 guidelines for diagnosis and severity grading of acute cholangitis (with videos).J HepatobiliaryPancreat Sci. 2013;20:24-34.

9. Gomi H, Takada T, Hwang TL, Akazawa K, Mori R, Endo I, et al. Updated comprehensive epidemiology, microbiology, and outcomes among patients with acute cholangitis.J HepatobiliaryPancreat Sci. 2017;24:310-8

10. Rhodes A, Evans LE, Alhazzani W, Levy MM, Antonelli M, Ferrer R, et al Surviving Sepsis Campaign: International Guidelines for Management of Sepsis and Septic Shock:2016. Intensive Care Med. 2017;43:304-77.

11. Rupp C, Bode K, Weiss KH, Rudolph G, Bergemann J, Kloeters-Plachky P, et al Microbiological assessment of bile and corresponding antibiotic treatment. Medicine (Baltimore).2016;95:e2390.PMID:26962768

12. Sahu MK, Chacko A, Dutta AK, Prakash JA. Microbial profile and antibiotic sensitivity pattern in acute bacterial cholangitis. Indian J Gastroentero 2011;30:204-208.PMID:22006165

13. BaeWK, Moon YS, Kim JH, Lee SH, Kim NH, Kim KA, et al. Microbiologic study of the bile culture and antimicrobial susceptibility in patients with biliary tract infection [abstract in English]. Korean J Gastroenterol 2008;51:248-54. PMID: 18516004

14. Shenoy SM, Shenoy S, Gopal S, Tantry BV, Baliga S, Jain A Clinicomicrobiological analysis of patients with cholangitis. Indian J Med Microbiol 2014;32:157-160.PMID:24713902

15. Csendes A, Burdiles P, Maluenda F, Diaz JC, Csendes P, Mitru N. Simultaneous bacteriologic assessment of bile from gallbladder and common bile duct in control subjects and patients with gallstones and common duct stones. Arch Surg 1996;131:389-94.PMID:8615724

16. Shivaprakasha S, Harish R, Dinesh KR, Karim PM. Aerobic bacterial isolates from choledochal bile at a tertiary hospital. Indian J PatholMicrobiol 2006;49:464-7.PMID:17001925

17. Chang WT, Lee KT, Wang SR, Chuang SC, Kuo KK, Chen JS, et al. Bacteriology and antimicrobial susceptibility in biliary tract disease: an audit of 10-year's experience. Kaohsiung J Med Sci 2002;18:221-8.PMID: 12197428

18. Kiesslich R, Holfelder M, Will D, Hahn M, Nafe B, Genitsariotis R, et al Interventional ERCP in patients with cholestasis. Degree of biliary bacterial colonization and antibiotic resistance [abstract in English]. Z Gastroenterol 2001;39:985-92.PMID: 11753782

19. Negm AA, Schott A, Vonberg RP, Weismueller TJ, Schneider AS, Kubicka S, et al. Routine bile collection for microbiological analysis during cholangiography and its impact on the management of cholangitis. GastrointestEndosc 2010;72:284-291.PMID:20541201

20. Pitt HA, Cameron JL. Acute Cholangitis. In: Way LW, Pelligrini CA, editors. Surgery of gall bladder \& bile ducts. Pennsylvania, USA:WB Saunders; 1987. p. 295313.

21. Rerknimitr R, Fogel EL, Kalayci C, Esber E, Lehman GA, Sherman S. Microbiology of bile in patients with cholangitis or cholestasis with and without plastic biliary endoprosthesis. GastrointestEndosc 2002;56:885-9. PMID: 12447303

22. Maluenda F, Csendes A, Burdiles P, Diaz J. Bacteriological study of choledochal bile in patients with common bile duct stones, with or without acute suppurative cholangitis. Hepato-gastroenterology 1989;36:132-135. PMID:2502489 